\title{
THE DEVELOPMENT AND IMPLEMENTATION OF MATH PROJECTS IN A HEI - EXPECTATIONS, OBJECTIVES, EXPERIENCES AND ANALYSIS
}

\author{
Ana Paula Lopes ${ }^{1}$, Filomena Soares ${ }^{2}$ \\ ${ }^{1}$ Polytechnic Institute of Porto (IPP) / ISCAP - CICE / UIE (PORTUGAL) \\ ${ }^{2}$ Polytechnic Institute of Porto (IPP) / ESEIG (PORTUGAL)
}

\begin{abstract}
An overwhelming problem in Math Curriculums in Higher Education Institutions (HEI), we are daily facing in the last decade, is the substantial differences in Math background of our students. When you try to transmit, engage and teach subjects/contents that your "audience" is unable to respond to and/or even understand what we are trying to convey, it is somehow frustrating. In this sense, the Math projects and other didactic strategies, developed through Learning Management System Moodle, which include an array of activities that combine higher order thinking skills with math subjects and technology, for students of HE, appear as remedial but important, proactive and innovative measures in order to face and try to overcome these considerable problems. In this paper we will present some of these strategies, developed in some organic units of the Polytechnic Institute of Porto (IPP).

But, how "fruitful" are the endless number of hours teachers spent in developing and implementing these platforms? Do students react to them as we would expect? Do they embrace this opportunity to overcome their difficulties? How do they use/interact individually with LMS platforms? Can this environment that provides the teacher with many interesting tools to improve the teaching - learning process, encourages students to reinforce their abilities and knowledge? In what way do they use each available material - videos, interactive tasks, texts, among others? What is the best way to assess student's performance in these online learning environments? Learning Analytics tools provides us a huge amount of data, but how can we extract "good" and helpful information from them?

These and many other questions still remain unanswered but we look forward to get some help in, at least, "get some drafts" for them because we feel that this "learning analysis", that tackles the path from the objectives to the actual results, is perhaps the only way we have to move forward in the "best" learning and teaching direction.
\end{abstract}

Keywords: Online Learning, Innovation, Technology in Teaching and Learning, Mathematics, Learning Analytics.

\section{INTRODUCTION}

Moodle (Modular Object Oriented Developmental Learning Environment) platform is an Open Source (OS) Learning Management System (LMS) that was developed by Martin Dougiamas ([1], [2]), founded on pedagogical principles, which aims to provide a diversity of features to support lecturers in creating and managing online modules. Moodle is used for blended learning, distance education, flipped classroom and other e-learning projects. From students' viewpoint, Moodle offers a virtual learning environment (VLE) that can add value or enlarge their studies by giving them access to learning materials, activities, assignments, among many other potential figures and tasks.

There are several environments that meet a set of features for creating and structuring of courses in the distance commonly recognised as LMS. Some of these environments utilized for creating and managing online courses are: Moodle, TelEduc, BlackBoard, WebCT, Toolbook, TopClass Server, among others. These present some remarkable differences, starting in the language they were developed to specific features they actually offer. All LMS central objective is to centralize and simplify administration and management procedures in the teaching and learning practice, through e-learning. These systems cover the entire process of distance learning, possessing interface, setting apart students' management features from teachers and tutors, differentiating several administrative tasks and even administrator profiles. In this sense, it helps all staff and students to plan their learning processes, allowing them to work together, through the exchange of knowledge and information [3].

Amongst the main features of e-learning platforms we can refer flexibility, accessibility, focusing on the student, the economy or rationalization of resources, interactivity and enhancement of the student 
role. The courses that are developed on the web have the advantage of providing the content for students anywhere in the world, faster than the other conventional methods.

VLEs are usually used in both Distance and On-Campus Learning, and it looks like that Moodle is one of the most commonly deployed systems as up to January 2016 it has over 80 million registered users, both teachers and students, in 224 countries and it is used in more than 9 million courses [4].

Conscious that the ability to change in Higher Education Institutions (HEI) is crucial to the sustainability of the educational progress, and that student's "troubles" with mathematical concepts do not end in High School, a group of Mathematics lecturers from the Oporto School of Accounting and Administration (ISCAP) developed a new online project in Moodle, called MatActiva, in order to support their students and promote their self-study autonomy. Nowadays students, frequently, reveal some difficulties when dealing with logical/mathematical reasoning, which often are reflected in simple tasks performance leading to an increasing disregard in relation to Mathematics in general. Over the past few years we have found that a major cause for the failure in Mathematics courses in our HEI is that many students have a "weak preparation" in mathematical basis. The project is a kind of "online tutor", being one of its main objectives, as we have already stated, study support and the development of Math skills directly related with the Curricular Units (CU) that belong to the scientific area of Mathematics, and it was built in a pure e-learning format [5]. In the beginning, this project was a resource to carry out learning objectives related with the content covered in the UC Mathematics of the first year of several course degrees in ISCAP, but quickly the project expanded to other CU. From the activity of students and teachers in the Moodle platform a huge amount of data ends up being recorded, with great potential for management, which most of the times is not used. The trace data (or log data) recorded by LMS contains time-stamped events about views of specific resources, attempts and quizzes completion, or discussion messages viewed or posted. Data mining techniques are commonly applied to identify patterns in these trace data. The interpretation of these patterns can be used to improve our understanding of learning and teaching processes, predict the achievement of learning outcomes, promote informed interventions and support decisions on resource allocation. This "process" has been described as Learning Analytics (LA) by [6]. One of the purposes of the LA is related to the management and analysis of these data, converting them into understandable and clear information so that HEI heads and workers may control actions and improve their decision making. According to [7], learning analytics is defined as the measurement, collection, analysis and reporting of data about learners and their contexts, for purposes of understanding and optimizing learning and the environments in which it occurs. The 2013 Horizon Report [8], describes LA as the "Field associated with deciphering trends and patterns from educational big data, or huge sets of studentrelated data, to further the advancement of a personalized, supportive system of higher education." The field of LA has received a lot of attention as a means for addressing institutional teaching and learning problems linked to the early identification of students at-risk of attrition or academic failure [9]. In the LA development and use, the HEl face two main challenges: the technological and the educational challenge. The first one is related with the HEI capability to develop software that enables deeper modes of extraction, aggregation and visualization of data and preparation of reports to make them into Analytics, while the second one is related to the HEl actors aptitude to manage and optimize the use of information in management and enhance the effectiveness of the teaching learning process [10]. Learning analytics is a fast-growing area of Technology-Enhanced Learning (TEL) research [11].

In this paper we will describe the process of designing and developing a LA system to evaluate the integration of Moodle in the teaching and learning process in higher education, which aggregates data from automated reporting from the MatActiva platform.

\section{THE PROJECT}

The ISCAP started in 2007 the Project "MatActiva". This Project is aimed at extending the e-learning services offered by the Faculty to its students and enriching the traditional teaching of Mathematics with the new technologies available nowadays. If we consider that students' knowledge "construction" can succeed in two different ways, inside and outside the classroom context, then we are dealing with two types of learning, formal and informal. According to Garner [12], which recognize non-formal learning as any scholar activity that takes place outside of school, or even at school, but outside the classroom, we may say that MatActiva Project lies in the field of informal learning.

The general goals of the MatActiva Project are: 
- Break up with preconceived ideas about Mathematics, increasing student motivation for learning, having in mind that motivation facilitates the learning process, as well as improving the ratio of students with Mathematics.

- Promote self-study in order to stimulate self-responsibility, in the teaching and learning process of each student.

- Develop general mathematical skills given their important role in several and common activities; currently any individual needs to use Mathematics as a tool in their daily life, so it's important that students improve their mathematical ability, based on logical reasoning development, and get the necessary skills to understand and project solution strategies for real-life situations.

The main goal of the project is to improve performance levels, skills and student success to all CU from scientific area of Mathematics.

MatActiva is developed in Moodle which allows the use of TEX language to create materials with mathematical symbols (one of the major problems when typing math texts). Making use of this feature and the goodwill of teachers directly involved (given the lack of financial resources), several interactive user friendly resources were developed. Based on educational teaching and learning principles, this Project is, at the present, used for blended learning, distance education and flipped classroom in ISCAP, making use of its several separated sections (see Table 1).

Table 1 - MatActiva Project Sections

\begin{tabular}{|l|l|}
\hline \multicolumn{1}{|c|}{ Mection } & \multicolumn{1}{|c|}{ MatActiva Sections } \\
\hline About Us - Sobre Nós & $\begin{array}{l}\text { This section provides contacts and published news related to the Project } \\
\text { specifically and Mathematics in general }\end{array}$ \\
\hline Mathematics Zero - & $\begin{array}{l}\text { Here we find, among others: } \\
\text {-Theoretical elementary notes that help to consolidate necessary } \\
\text { requirements to all the CU from Mathematics area; } \\
\text { - Syllabus - Program Contents covered in Mathematics Zero (MZ) (items } \\
\text { from Elementary and Secondary school); } \\
\text { - Tutorial Video Lectures about several Mathematics subjects, followed by } \\
\text { exercises that can be performed online, in which the student automatically } \\
\text { receives the quantitative results, the feedback for each question and a } \\
\text { proposal for a comprehensive solution; } \\
\text { - Diagnostic tests - with several levels, according to the Elementary and } \\
\text { Secondary Education programs, that can be done online. They offer } \\
\text { quantitative results and respective feedback to the student which may } \\
\text { have, automatically, a perception of their level of performance. Students } \\
\text { still have access to a draft solution step by step (currently MZ Issues Base } \\
\text { has over 350 questions). }\end{array}$ \\
\hline Learning - Aprendendo & $\begin{array}{l}\text { Exploratory section with numerous documents and several links but with } \\
\text { different goals from the previous sections: } \\
\text { - Taking advantage of pedagogical innovation and temporal flexibility, } \\
\text { supporting individual and collaborative study, it allows students who do } \\
\text { not attend assiduously to lectures and/or who have difficulties, to use the } \\
\text { supporting documents provided by the Project at any time. The goal is not } \\
\text { to replace classes, but to complement these, going through basic } \\
\text { Mathematic concepts that support and fundament the subjects covered in } \\
\text { several CU of Mathematics area (issues like Algebra, Financial Calculus, } \\
\text { Statistics and Mathematical Analysis), providing students structure a can } \\
\text { be built from a more solid foundation; } \\
\text { - Links to webpages with mathematical resources that explore different } \\
\text { contents of Mathematics. }\end{array}$ \\
\hline
\end{tabular}




\begin{tabular}{|c|c|}
\hline Tests - Testes & $\begin{array}{l}\text { It presents a set tests with multiple choice, true/false and matching } \\
\text { questions. With these tests we intend to offer to students, working } \\
\text { instruments to promote self-regulation of their learning commitment and } \\
\text { help them to raise their own performance levels. A Question Pool was } \\
\text { created from the ground up, grouped into categories and subcategories, } \\
\text { on various topics: } \\
\text { - Algebra ( } 315 \text { questions) } \\
\text { - Mathematical Analysis ( } 375 \text { questions) } \\
\text { - Statistics ( } 306 \text { questions) } \\
\text { - Financial Mathematics ( } 293 \text { questions) } \\
\text { The combination of questions in each category is randomized and it } \\
\text { generates a huge number of different tests that students can solve online, } \\
\text { wherever they are and at a time that suits them. The tests allow multiple } \\
\text { attempts, providing automatically quantitative results and each attempt is } \\
\text { corrected immediately. For each wrong answer the feedback is presented } \\
\text { with a suggested step by step solution, in order to help students to } \\
\text { understand what went "wrong" with their answer, providing and promoting } \\
\text { self-assessment and skill development. }\end{array}$ \\
\hline Doubts - Dúvidas & $\begin{array}{l}\text { Doubts Forum is a section addressed to clarify several issues related to } \\
\text { theoretical subjects and exercises, moderated by teacher leading the } \\
\text { project (head of the project - HP). Students place their questions online, } \\
\text { which are also online clarified by the HP or by other students. It is an open } \\
\text { space where interaction occurs effectively, supporting students in the } \\
\text { study, in a targeted way, enabling and encouraging their self-confidence. }\end{array}$ \\
\hline $\begin{array}{l}\text { MathChallenge - } \\
\text { MatDesafio }\end{array}$ & $\begin{array}{l}\text { This is a competition opened to all ISCAP community, with a set 6-7 } \\
\text { challenges/problems, proposed throughout the school year in order to } \\
\text { develop the interest of students in Mathematics and logical reasoning, } \\
\text { never forgetting that learning Mathematics should also be made through } \\
\text { research and investigative activities. } \\
\text { Note that challenges are facilitating factors to communication and } \\
\text { reasoning, reinforcing general motivation, developing different and better } \\
\text { ways to look at Mathematics, in particular. Taking advantage of students' } \\
\text { natural enthusiasm for gambling situations, confronting students with } \\
\text { Mathematical Challenges, that promote logical and organized reasoning, } \\
\text { will certainly help them to follow an educational successful path. }\end{array}$ \\
\hline ETC - ETC & $\begin{array}{l}\text { This section is a kind of Math "Fun Zone" with a Games Blog and } \\
\text { Mathematical Curiosities. The curiosity stimulation and gambling interest } \\
\text { may be a source of pleasure and reflection for students, allowing them to } \\
\text { develop their concern for Mathematics and improve their level of success. }\end{array}$ \\
\hline
\end{tabular}

\section{LEARNING ANALYTICS}

The assessment of students' performance in online learning environments is a challenging and demanding task for educators. Educators who adopt online learning systems are often required to constantly adapt and evolve their online courses to assure high performance and learning efficiency of their students [13]. By having access to the learning analytics on students' conclusion of lessons and quiz scores, educators should have a better sense of: students' ability to follow and understand the course contents; the topics students found difficult; students' social interactions and knowledge contributions, etc. Therefore, educators should "desire" a LMS that offers learning analytics on their online courses. A typical LA process starts with the data-gathering step. In this stage, data is collected from different learners' activities when they interact with learning elements within a VLE. The next stage is the mining of the processed data, based on different mining techniques, such as clustering, classification, association rule mining, and social network analysis. Then, the results of the mining process can be presented as a widget, which might be included into a VLE. With appropriate graphical visualizations of the analyzed data, educators will be able to understand and interpret the information 
represented, reflect on the impact of their teaching method on the learning behavior and performance of their students, and draw first conclusions about the effectiveness of their teaching model.

The Moodle platform provides the teacher/administrator different analytical tools with a wide range of information reports on the numerous activities carried out by their students in a particular subject, which can be an important tool to improve and modify the subject in question. Thus, there are a number of reports, blocks and other plugins for Moodle, that provide learning analytics and in MatActiva we have several standard and additional plugins as we can see in Table 2.

Table 2 - MatActiva Moodle Plugins

\begin{tabular}{|l|l|l|l|}
\hline \multicolumn{1}{|c|}{ Plugin } & Plugin Type & Standard/Additional & \multicolumn{1}{c|}{ Useful for } \\
\hline Engagement Analytics & $\begin{array}{l}\text { Block, Report, } \\
\text { Activity module }\end{array}$ & Additional & Educators \\
\hline Logs & Report & Standard & $\begin{array}{l}\text { Teachers, Admins, } \\
\text { Decision-makers }\end{array}$ \\
\hline Live Logs & Report & Standard & Teachers, Admins \\
\hline Activity Report & Report & Standard & Teachers \\
\hline Course Participation & Report & Standard & Teachers \\
\hline Course Dedication & Block & Additional & Teachers, Students \\
\hline Gismo & Block & Additional & Teachers \\
\hline Google Analytics & Block & Additional & Teachers \\
\hline
\end{tabular}

A Course Activity Report, shows the number of views for each activity and resource (see Fig.1). The Activity column shows the icon for the activity type and the name of the activity. The Views column tells how many times each item has been viewed. The Last access column tells the date the item was last viewed, and elapsed time since it was last viewed.

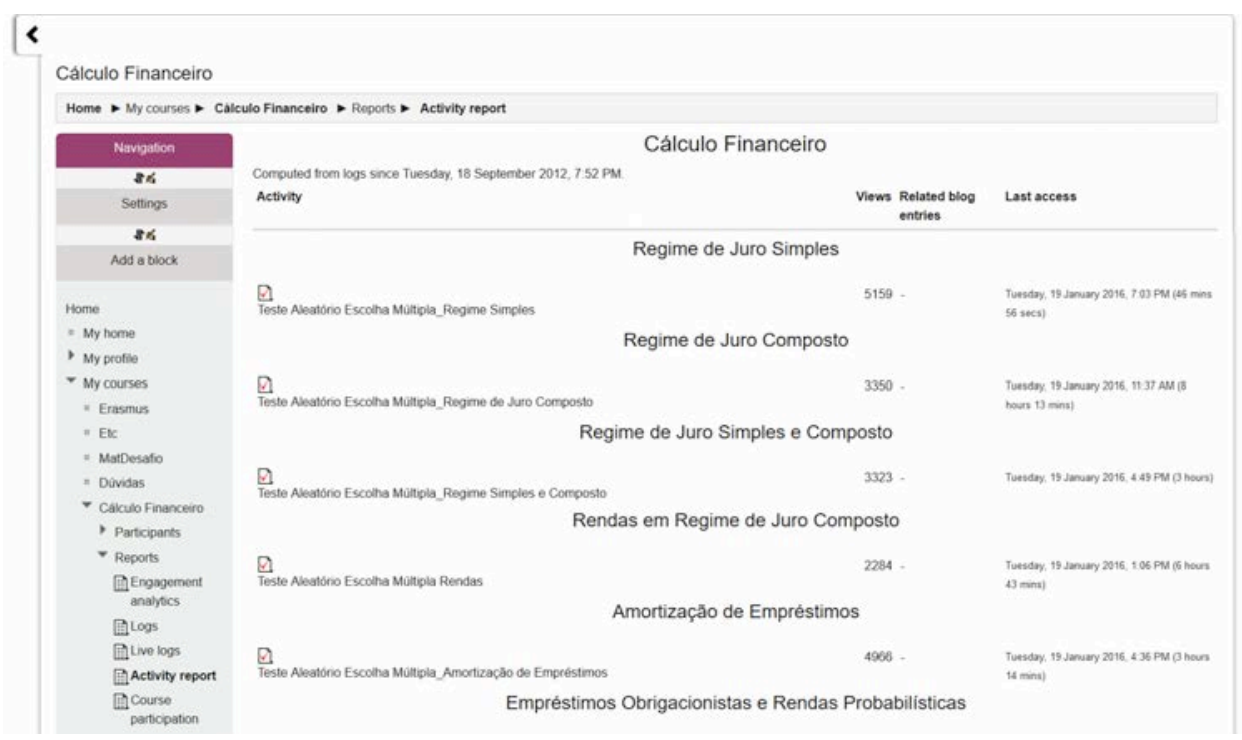

Figure 1 - Activity report for Financial Calculus (Cálculo Financeiro) Course

Course logs allow educators to see which resources or activities have been accessed and when. By selecting some of the configurable options, one can look at the activity of particular students on specific days for the selected content. For example, Fig. 2 shows part of a report, listing students who viewed the Financial Calculus (Cálculo Financeiro) Course, on 10 January 2016. 


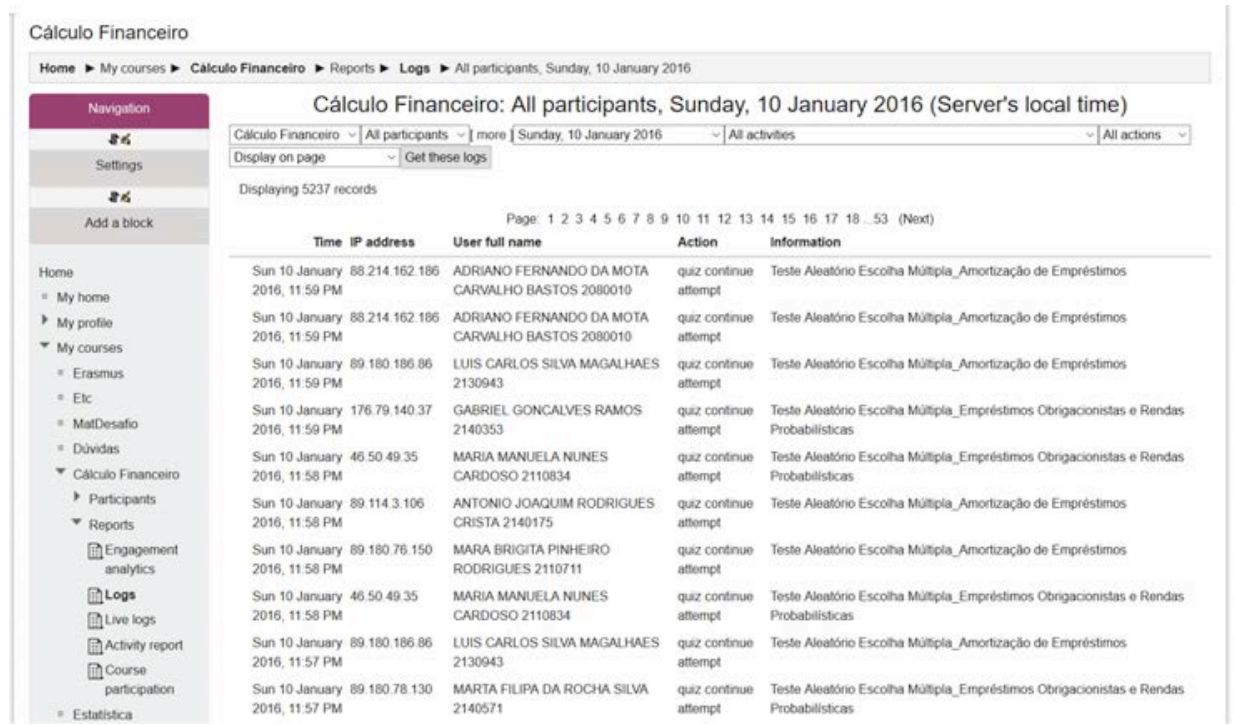

Figure 2 - Report on students who viewed Financial Calculus Course on 10 January 2016

Gismo is a visualization tool for Moodle, which use log data, process them and finally produces graphical representations that can be used by teachers in order to examine social, cognitive and/or behavioral student interactions. The tool may be incorporated in Moodle as a supplement block within the graphics environment, only visible to the teacher. It provides analytic statistical representations and shows a general "picture" of the students as a whole, analyzing a more general learning process of all the students on all subjects [14]. It can also provide analytical statistic representations for specific students, resources and activities.

For instance, we can have an overview of which days in a particular section was more accessed, in a certain period of time (see Fig. 3).

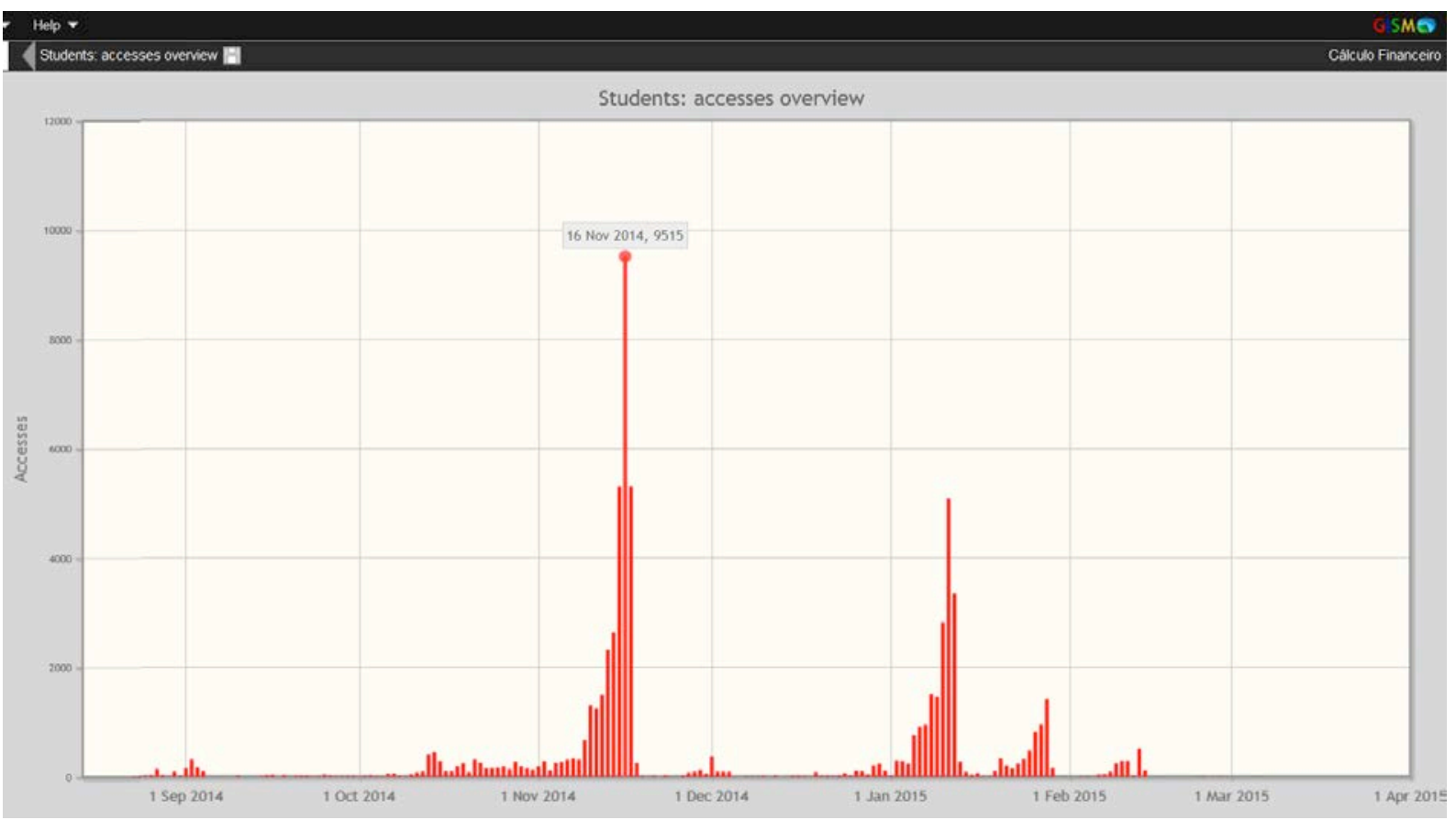

Figure 3 - Graph reporting the student's accesses to Financial Calculus Course, from September 1, 2014 to April 1, 2015

Course dedication - This block allows to look at the estimated dedication time to a Moodle course by its participants. It provides three possible views: 
- Dedication time of the course: calculates total dedication time, mean dedication time and connections per day for each student.

- Dedication time of a group: the same but only for chosen group members.

- Dedication of a student: detailed sessions for a student with start date \& time, duration and ip (see Fig. 4).

\section{Course dedication (mins)}

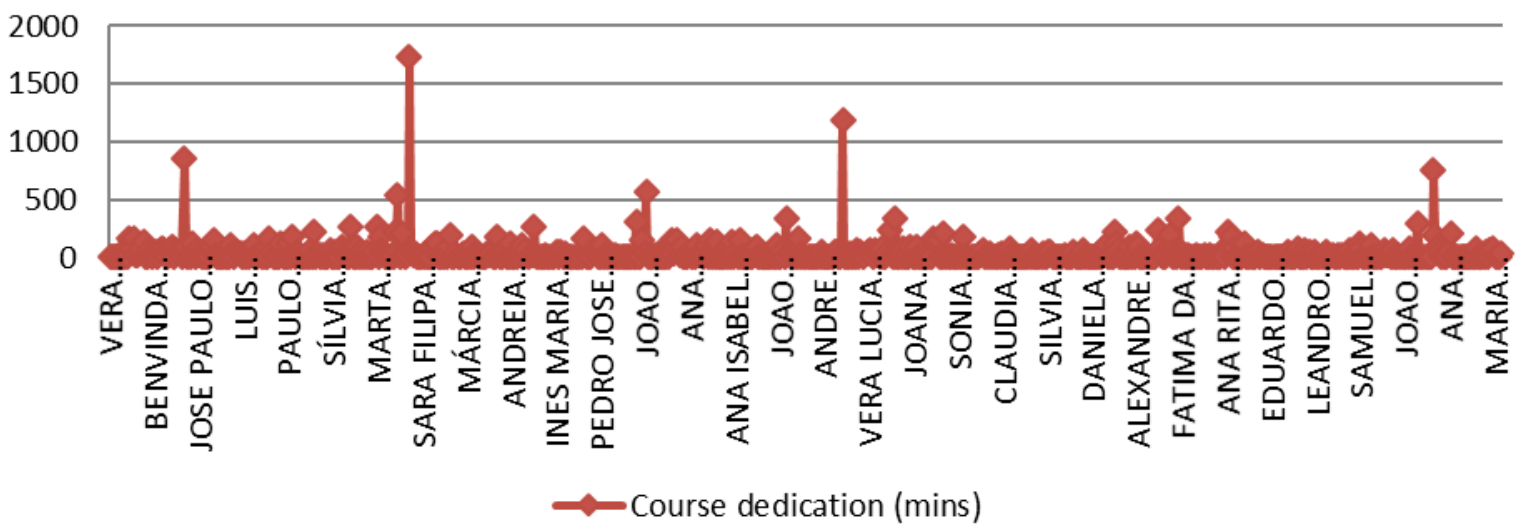

Figure 4 - Course Dedication of some students in Mathematics Zero Course

Google analytics - The Moodle Google Analytics plugin help us to analyze Moodle site traffic. It collects data regarding website's Audience, Behavior, Conversions, Acquisition and Real time visitors. It provides many tools, like for example, the Users Flow report - a graphical representation of the paths users took through your site, from the source, through the various pages, and where along their paths they exited your site. The Users Flow report - that allows the comparison of traffic volumes from different sources, examine traffic patterns through the site, and troubleshoot its efficacy (see Fig. 5).

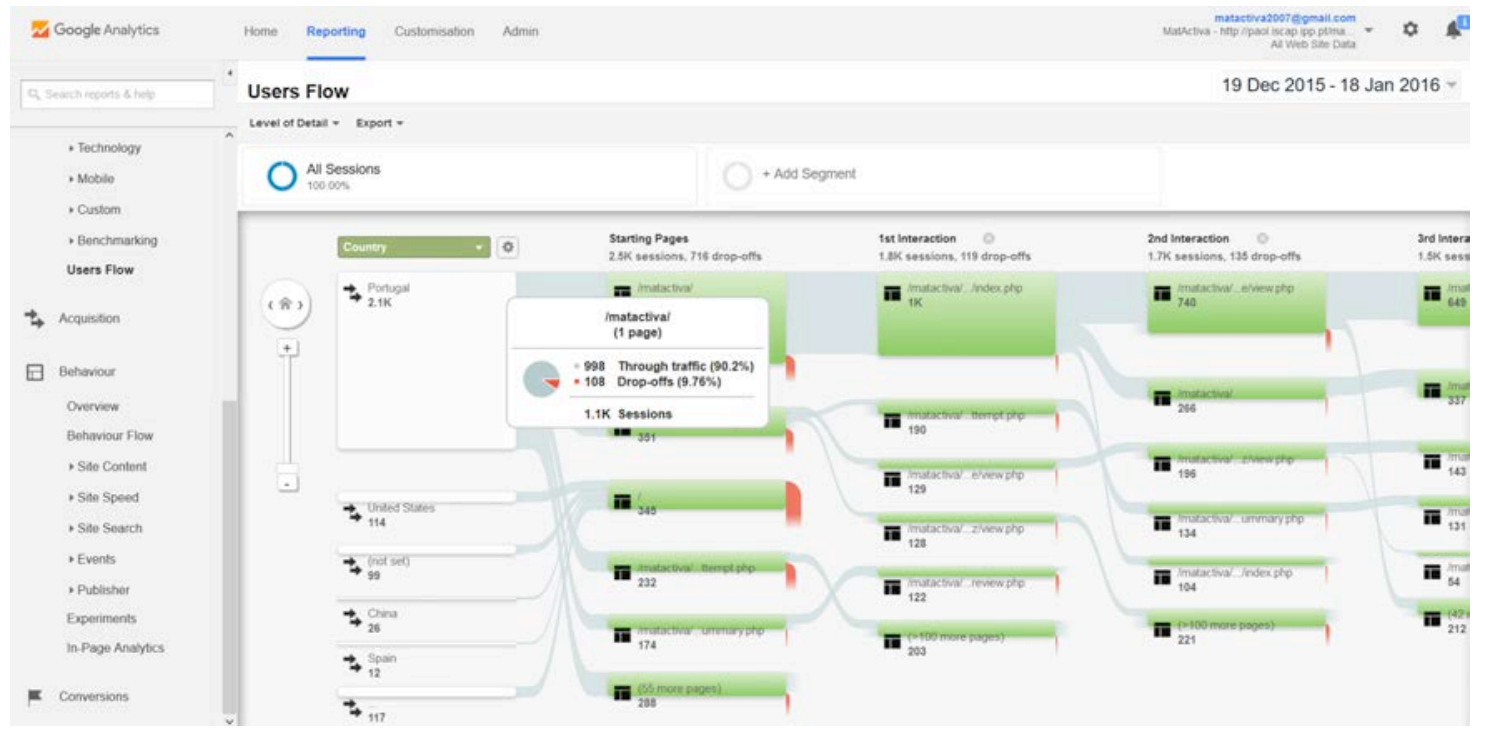

Figure 5 - Users Flow available in MatActiva Google Analytics

Another available tool is the Behavior Flow report. It visualizes the path users traveled from one page or Event to the next. This report can help you discover what content keeps users engaged with your site. The Behavior Flow report can also help identify potential content issues (see Fig. 6). 


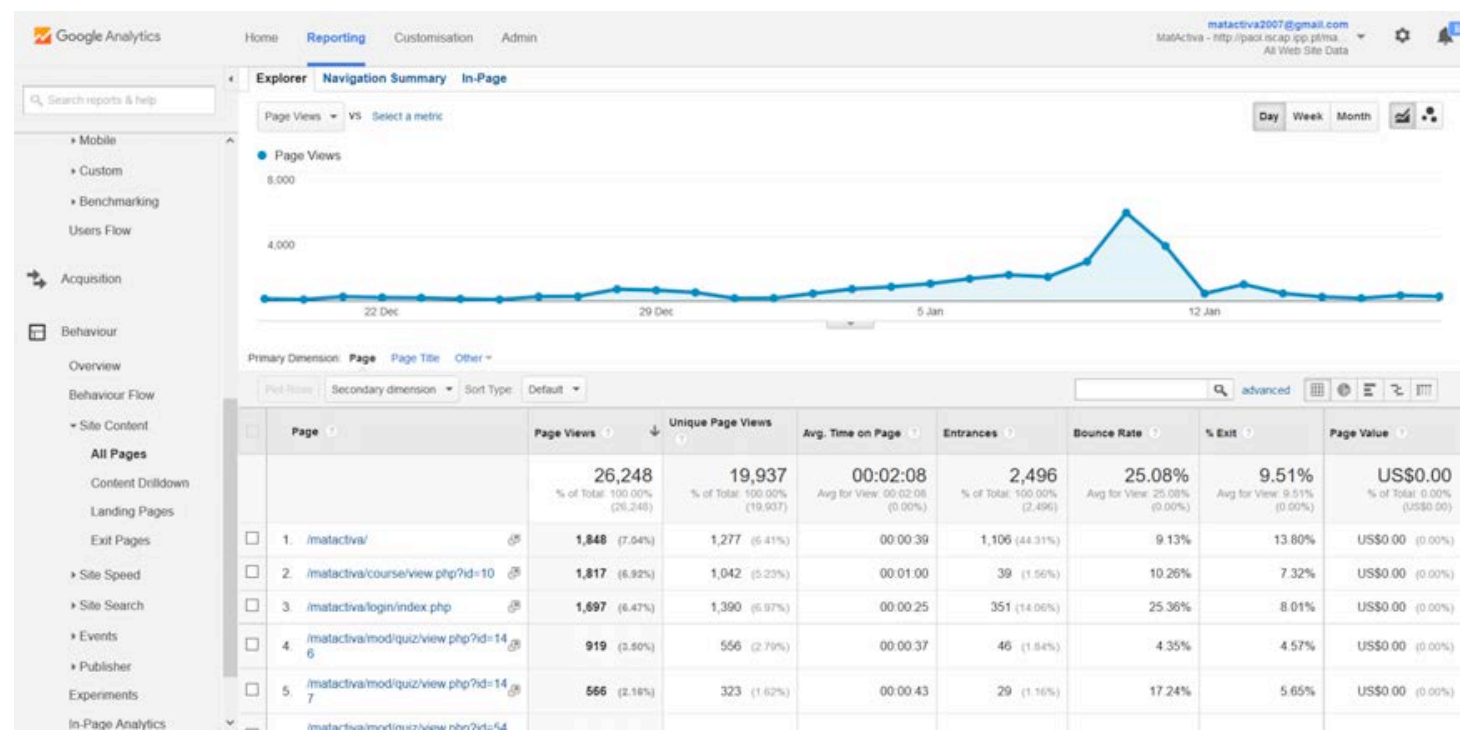

Figure 6 - Behavior Flow available in MatActiva Google Analytics

In summary, there are many analysis tools that can potentiate the study of students/users' behavior, developed over the past years. According to [15] Learning Analytics is a helpful instrument that facilitates decision procedures, which consists of five stages: data collection, reporting, forecasting, act and refine. These steps begin with the collection of data since data are the foundation of any study, which will be subsequently selected and organized. Then, experts will carry out the study and use analysis tools that allow them to review the information, identify trends and patterns in data using statistical analysis that allow predict and act on this forecast, aiming to reformulate the project for further improvement.

\section{CONCLUSION}

In the past few years, Learning Analytics has emerged as a significant area of research into technology-enhanced learning. It is certain that new technologies play a fundamental and even common role in today's society.

Moodle is one of the e-learning platforms most commonly used worldwide, having a significant implementation in distance learning and boosted by the fact that it is distributed in an open source basis, facilitating the spread of information and knowledge accessibility to new universes of users. The MatActiva Project uses Moodle platform to communicate and spread information and knowledge. In this project students have access to a number of support materials, to complement and assist the development of Mathematical skills and also support the study of the contents taught in the $\mathrm{CU}$ of this scientific area. It also has available a variety of quizzes, as well as tutorial video lectures about several subjects related to Mathematics. With the data collected we tried to find a way to improve students' performance and results, since the LA offers an unprecedented view of teaching and learning. Provided with better knowledge, those in charge for the project can define and "measure" learning goals achievement, evaluating the success of several courses. The LA also allows to evaluate the online behavior of students and to explore the meaning of this behavior, to influence the choices that support the pedagogical practices. In future, by using a Learning Analytics system we would like to assess the integration of the LMS in the overall teaching and learning process.

\section{REFERENCES}

[1] Dougiamas, M. (2001). Moodle: open-source software for producing internet-based courses. http://dougiamas.com/

[2] Dougiamas, M. and Taylor, P.C. (2003) Moodle: Using Learning Communities to Create an Open Source Course Management System. Proceedings of the EDMEDIA 2003 Conference, Honolulu, Hawaii. 
[3] Lopes, A., (2011). Teaching with Moodle in Higher Education. In proceedings of INTED2011 International Technology, Education and Development Conference. Cd ISBN: 978-84-6147423-3, and in Abstracts Cd ISBN: 978-84-614-7422-6

[4] Moodle.Org, Moodle Statistics (2016). Retrieved from http://moodle.net/stats (last accessed January, $18^{\text {th }} 2016$ ).

[5] Azevedo, J., Torres, C. Lopes, A. e Babo, L. (2009). Enhancing Math Skills with Moodle, ICERI2009, pp. 2367-2377, ISBN: 978-84-613-955-7.

[6] Siemens, G., \& Gašević, D. (2012). Special issue on learning and knowledge analytics. Educational Technology \& Society, 15(3), 1-163

[7] Society for Learning Analytics Research (SoLAR), (2012). Society for learning analytics research. Retrieved from http://www.solaresearch.org/mission/about/ (last accessed January, $14^{\text {th }}$ 2016).

[8] Horizon Report: 2013 Higher Education Edition (2013). Retrieved from http://www.nmc.org/pdf/2013-horizon-report-HE.pdf (last accessed January, 10 ${ }^{\text {th }} 2016$ ).

[9] Dawson, S., Gašević, D., Siemens, G., \& Joksimovic, S. (2014). Current state and future trends: A citation network analysis of the learning analytics field. Proceedings of the Fourth International Conference on Learning Analytics and Knowledge (pp. 231-240). New York, NY, USA: ACM. http://dx.doi.org/10.1145/2567574.2567585

[10] Ferguson, R., (2012). The state of learning analytics in 2012: A review and future challenges. Technical report KMI-12-01. Milton Keynes, UK: Knowledge Media Institute, The Open University.

[11] Ferguson, Rebecca (2012). Learning analytics: drivers, developments and challenges. International Journal of Technology Enhanced Learning, 4(5/6) pp. 304-317.

[12] Garner, N., Hayes, S. M., \& Eilks, I. (2014). Linking formal and non-formal learning in science education - A reflection from two cases in Ireland and Germany. Sisyphus Journal of Education, 2(2), 10-31.

[13] Gasevic, D., Jovanovic, J., \& Devedzic, V. (2007). Ontology-based annotation of learning object content. Interactive Learning Environments, 15(1), 1-26.

[14] Mazza R., and Botturi L. (2007). Monitoring an online course with the GISMO tool: A case study. Journal of Interactive Learning Research, vol. 18(2), pp.251 - 265, 2007.

[15] Oblinger, D. G. and Campbell, J. P. (2007). Academic Analytics, EDUCAUSE White Paper. 